\title{
Differential effects of PDCD4 depletion on protein synthesis in myoblast and myotubes
}

\author{
Dhanshri Kakade, Nushaba Islam, Naomi Maeda and Olasunkanmi A J Adegoke*
}

\begin{abstract}
Background: Reduced muscle mass is a hallmark of metabolic diseases like diabetes and cancer. The mammalian (mechanistic) target of rapamycin complex 1/S6 kinase 1 (mTORC1/S6K1) pathway is critical to the regulation of muscle protein synthesis and mass but its mechanism of action is not completely understood.

Results: Using L6 myotubes, we characterized the regulation of programmed cell death 4 (PDCD4), a recently described substrate of S6K1. The abundance, but not Ser67 phosphorylation, of PDCD4 was sensitive to amino acid and serum deprivation: values in starved cells were $4.5 \mathrm{X}$ of control $(P<0.001)$. Refeeding had opposite effects. Growth factors, compared to amino acids, appeared more critical in regulating PDCD4 abundance. Furthermore, inhibition of $\mathrm{MTORC1}$ or the proteasome prevented the refeeding-associated decrease in PDCD4 abundance. Amino acid and serum deprivation significantly increased PDCD4 binding to elF4A $(P<0.05)$; this was reversed during refeeding. PDCD4 depletion by RNA interference had no significant effect on phenylalanine incorporation into myotube mixed proteins in control cells but further suppressed (30\%) this measure in nutrient-deprived cells $(\mathrm{P}<0.0005)$. This was not observed in myoblasts. In starved myotubes, PDCD4 depletion further reduced the association of elF4G with elF4E.

Conclusion: Our data suggest that in myotubes, PDCD4 abundance is sensitive to nutritional manipulation in an mTORC1 and proteasome depended manner. Furthermore, the role of PDCD4 in regulating protein synthesis appears dependent on the developmental state of the cell.
\end{abstract}

Keywords: PDCD4, mRNA translation, S6K1, Protein synthesis, Skeletal muscle

\section{Background}

The mammalian (mechanistic) target of rapamycin complex 1/ribosomal protein S6 kinase 1 (mTORC1/S6K1) signalling is a critical regulator of skeletal muscle mass and metabolism, and mechanisms that regulate it are studied as possible targets for the treatment/prevention of loss of muscle mass in diverse muscle atrophying conditions $[1,2]$. However, the exact mechanism by which S6K1 regulates muscle mass and metabolism remains to be identified. Substrates of S6K1 proposed to mediate its actions are all factors that associate with or regulate mRNA translation initiation. These include the ribosomal protein S6 (S6) and the eukaryotic mRNA translation initiation factor 4B (eIF4B), both of which upon activation induce mRNA translation initiation. S6K1 also phosphorylates eukaryotic mRNA translation elongation factor 2 (eEF2) kinase, an

\footnotetext{
* Correspondence: oadegoke@yorku.ca

School of Kinesiology \& Health Science and Muscle Health Research Centre, York University, 4700 Keele Street, Toronto, Ontario M3J 1P3, Canada
}

inhibitor of mRNA translation (reviewed in $[3,4]$ ). In skeletal muscle, concurrent increase in phosphorylation of S6K1, S6 and eIF4B are observed in conditions that stimulate muscle protein synthesis, including resistance exercise, provision of amino acid, and stimulation with insulin/IGF-1 $[1,5,6]$. However, the functions/regulation of these substrates do not account for the actions of S6K1 in controlling mRNA translation initiation and muscle mass [6,7], suggesting a role for other substrates of this kinase.

Programmed cell death 4 (PDCD4), (also known as MA3, TIS (topoisomerase inhibitor-suppressed) [8], H731 [9], and interleukin-12 inducible human gene 197/15a [10] (reviewed in [11])), is a more recently discovered substrate of S6K1 [12]. In the hypo phosphorylated state, it binds to both eIF4A and eIF4G, leading to both the inhibition of the helicase activity of eIF4A and of the formation of eIF4F complex. These changes will lead to the suppression of translation of mRNA with secondary structures at their 
5 '-UTR ends $[13,14]$. Upon mitogen stimulation, activated S6K1 phosphorylates Ser67 in PDCD4. This targets it for ubiquitination by the ubiquitin protein ligase betatransducin repeat containing protein $(\beta$-TRCP) and subsequent degradation by the proteasome [12].

Much of what is known about PDCD4 is from cancer studies where PDCD4 is proposed to function as a cell cycle inhibitor/tumor suppressor. Loss of this protein is associated with invasion, progression or increased aggression of numerous, but not all [15], cancers, including ovarian [16], lung [17], breast [18], liver [19] and colon cancers [11]. As a substrate of mTORC1/S6K1, PDCD4 may mediate the effect of this kinase pathway on protein synthesis in skeletal muscle. However, not much is known about the role or regulation of PDCD4 in muscle, the tissue that is quantitatively the most important in whole body protein metabolism. It was recently shown that the abundance of PDCD4 in rat skeletal muscle is sensitive to feeding and food deprivation cycle: its abundance increased in skeletal muscle of food-deprived rats, but in fed or refed rats, its abundance decreased along with increase in muscle fractional protein synthesis [20]. These data suggest that interventions that regulate PDCD4 abundance may be explored in the treatment of muscle wasting, a feature of diseases like cancer, AIDS, and trauma. However this study was mainly correlative and did not examine whether or not mTORC1/S6K1 is required for PDCD4 regulation in muscle.

In the present work, using L6 myotubes, our specific objectives were to: 1 ) examine the requirement for mTORC1/ S6K1 and the ubiquitin proteolytic system in regulating PDCD4; 2) examine the contribution of amino acids vs. growth factors in mediating the effect of nutrition on PDCD4; and 3) determine whether nutritional status affects the interaction of PDCD4 with components of eIF4F. Because others have suggested that signalling pathways that regulate protein metabolism may be regulated differently in myotubes versus myoblasts [21] and because the regulation of PDCD4 may depend on cell type [22], we also assessed the effect of PDCD4 depletion by RNA interference (RNAi) on myotube total and myofibrillar protein synthesis.

\section{Results}

\section{Abundance of PDCD4 in L6 myotubes is sensitive to medium composition and requires $\mathrm{MTORC} 1$ and the proteasome}

Given the identification of PDCD4 as a substrate of mTORC1/S6K1 signalling, and the fact this kinase pathway is regulated by nutrients, we examined the effect of nutrient deprivation on the regulation PDCD4 in L6 myotubes. Neither $12 \mathrm{~h}$ of serum and amino acid deprivation nor refeeding in a complete medium had any significant effect on PDCD4 Ser67 (the residue targeted by S6K1) phosphorylation (Figure 1A, B). Furthermore, serum and amino acid deprivation had no effect on phosphorylation on Ser457, although phosphorylation on this residue was increased by refeeding (see Additional file 1). However, PDCD4 abundance increased more than four-fold in starved cells and decreased progressively with time during refeeding such that by $3 \mathrm{~h}$ of refeeding, values in re-fed cells were not different from control $(\mathrm{P}<0.05$, Figure $1 \mathrm{~A}, \mathrm{C})$. Incubation with rapamycin, an mTORC1 inhibitor, abolished the effect of refeeding on PDCD4 abundance (Figure 1A, C).

Because the ubiquitin system is implicated in the phosphorylation-dependent degradation of PDCD4, we incubated the cells with MG132, a proteasome inhibitor.

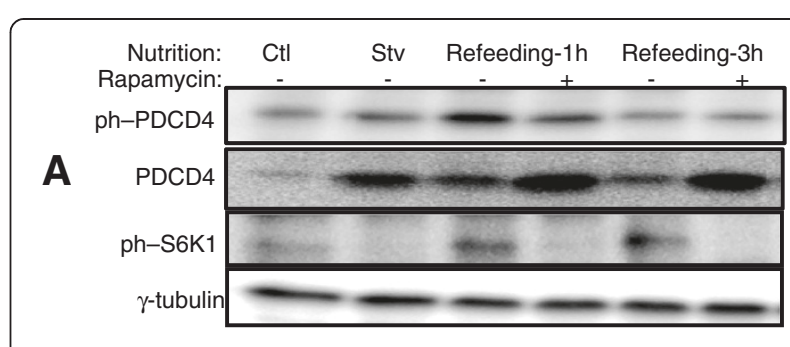

B

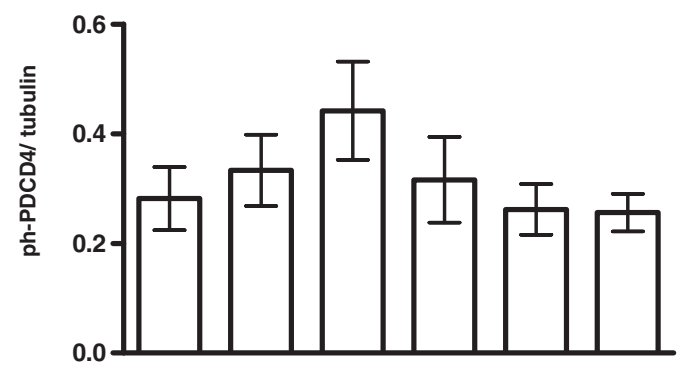

C

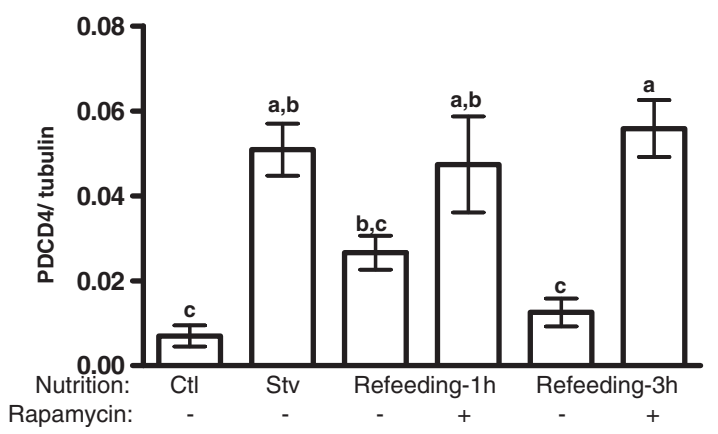

Figure 1 In L6 myotubes, PDCD4 abundance, but not phosphorylation, is sensitive to medium nutrient composition and requires $\mathrm{mTORC} 1$ function. L6 Myotubes were incubated in differentiation (Ctl) or starvation medium (serum-free, amino acid-free RPMI medium) for $12 \mathrm{~h}$. They were then harvested (Stv) or refed in the differentiation medium supplemented with DMSO (-) or $50 \mathrm{nM}$ rapamycin (+) for 1 or 3 h. (A) Phosphorylated (ph) and total PDCD4 (Ser67), ph-S6K1 (Thr389) and $\gamma$-tubulin were analyzed by immunoblotting. (B and $\mathbf{C}$ ) phosphorylated and total PDCD4 signals were expressed relative to $\gamma$ tubulin. Means \pm SE of 5-6 independent experiments; bars with different letters differ $(P<0.05)$. 
Like rapamycin, addition of MG132 prevented the disappearance of PDCD4 during re-feeding (Figure 2A, B).

\section{Growth factors, but not amino acids, regulate PDCD4 abundance}

The experiments above did not indicate whether the observed effects of refeeding were due to nutrients or growth factors. To address this question, we repeated the starvation experiment but re-fed the myotubes in either the differentiation medium, serum-free AMEM, or starvation medium supplemented with leucine, dialyzed FBS or horse serum. Only media that contained serum promoted the degradation of PDCD4 (Figure 3A, B).

\section{Association of PDCD4 with elF4A in L6 myotubes is sensitive to medium composition}

PDCD4 inhibits mRNA translation initiation at least in part by its binding to eIF4A and eIF4G. The amount of PDCD4 found in eIF4A immunoprecipitate was increased by starvation but fell gradually during refeeding, especially at $3 \mathrm{~h}$, at which time the values were not different from those observed in fed cells (Figure 4A, B). In another experiment, we carried out the reciprocal immunoprecipitation. The amount of eIF4A in PDCD4 immunoprecipitate was unchanged by treatments; however, because starvation

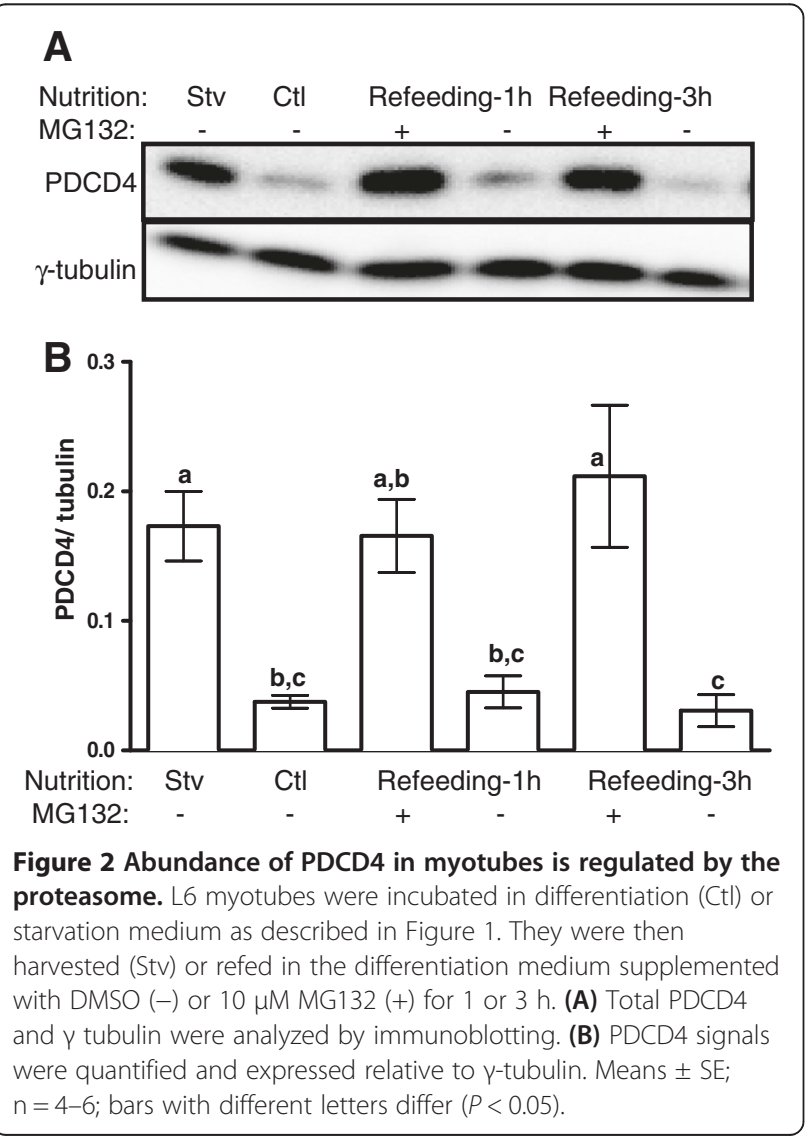

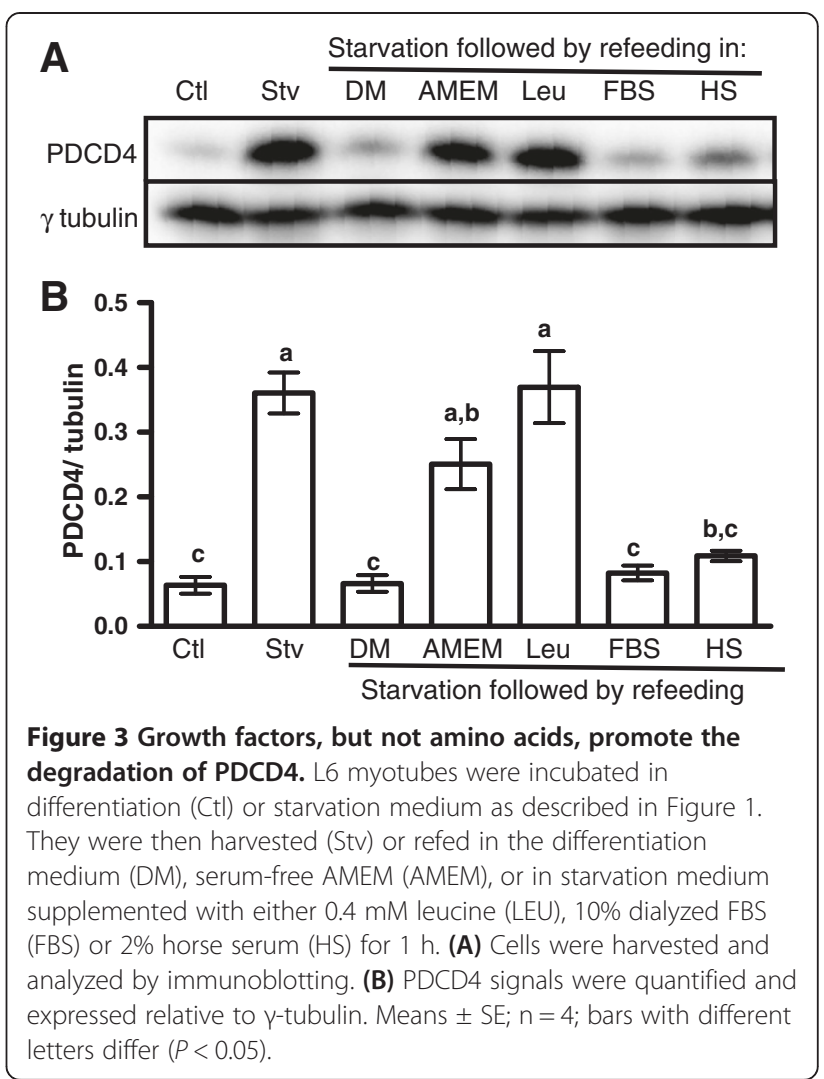

increased PDCD4 abundance in the immunocomplex, the ratio of eIF4A to PDCD4 was suppressed by starvation. This was reversed by refeeding (Figure 4C-D). In addition, the pattern of eIF4G association with PDCD4 was similar to that observed for eIF4A; however, the effect of refeeding was not seen until the $3 \mathrm{~h}$ time point (Figure $4 \mathrm{C}$ and $4 \mathrm{E}$ ). Finally we examined the effects of mTORC1 inhibition on the interactions. In all cases, the effect of refeeding on the interactions of PDCD4 with eIF4A and 4G was sensitive to rapamycin (Figure 4A-E).

\section{PDCD4 depletion in myotubes had modest effect on protein synthesis}

To examine the significance of PDCD4 in regulating myotube mixed protein synthesis, we used RNAi to deplete this protein (Figure 5A) and then measured incorporation of phenylalanine into myotube proteins. In fed cells $(\mathrm{Ctl})$, incorporation of phenylalanine into mixed proteins in cells deprived of PDCD4 was not different from the value in those treated with scrambled oligonucleotides (Scrambled siRNA: $2148 \pm 165$; PDCD4 siRNA \#1: $1924 \pm 91$, PDCD4 siRNA \#2: $1919 \pm 115 \mathrm{cps} / \mathrm{mg}$ protein, $\mathrm{P}>0.5$, Figure $5 \mathrm{~B})$. In cells deprived of serum but supplied with amino acids (i.e., serum-free AMEM), phenylalanine incorporation into proteins in cells treated with PDCD4 siRNA \# 1 was $86 \%$ of values in those treated with scrambled siRNA ( $P=0.11$, data not shown); the 


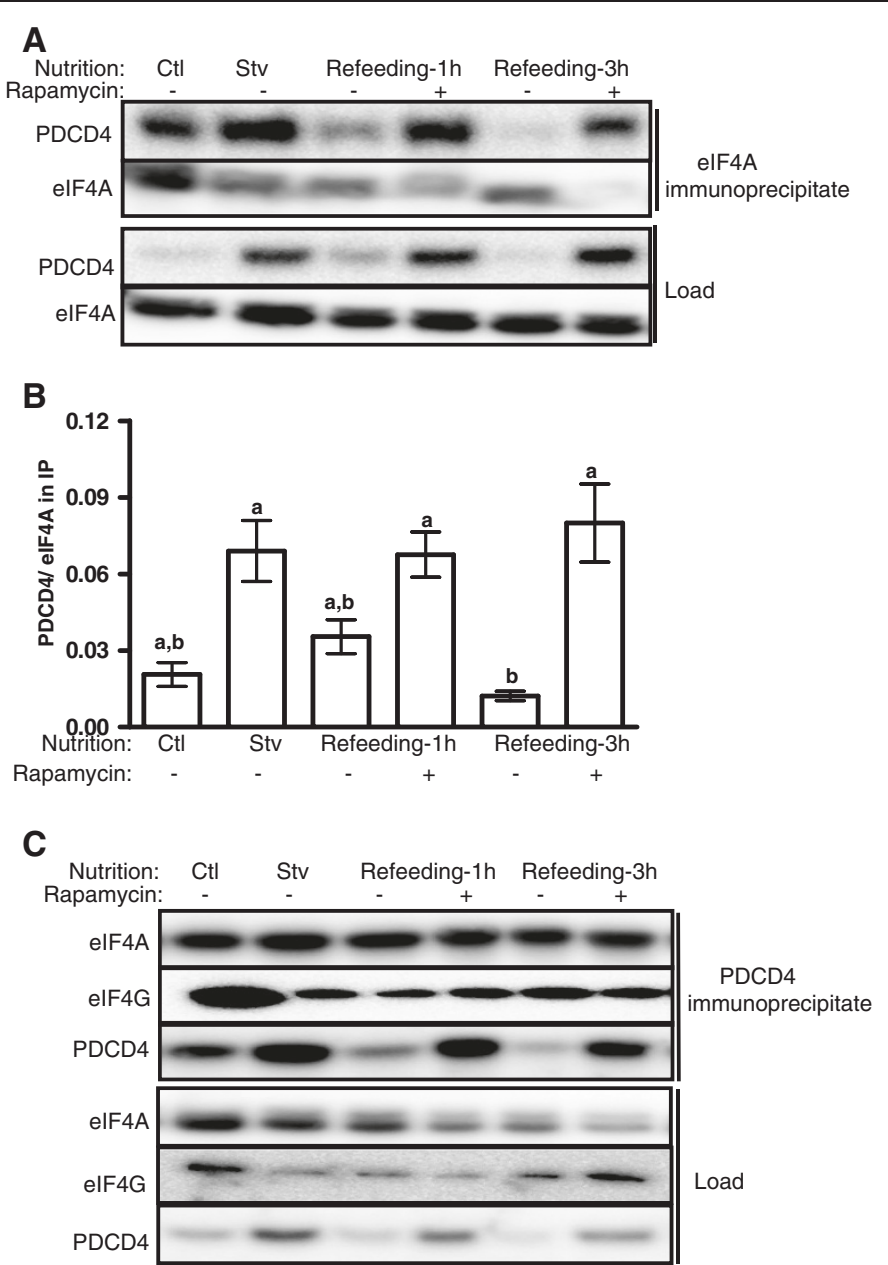

D

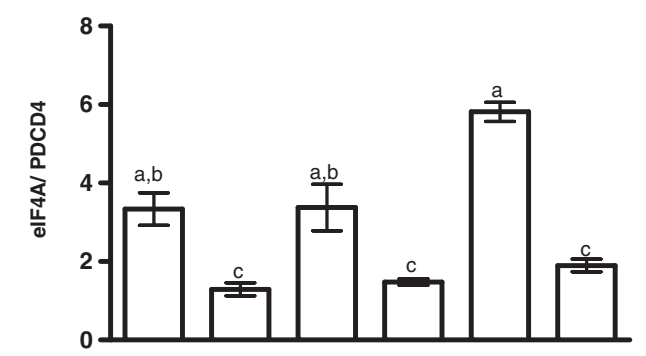

E

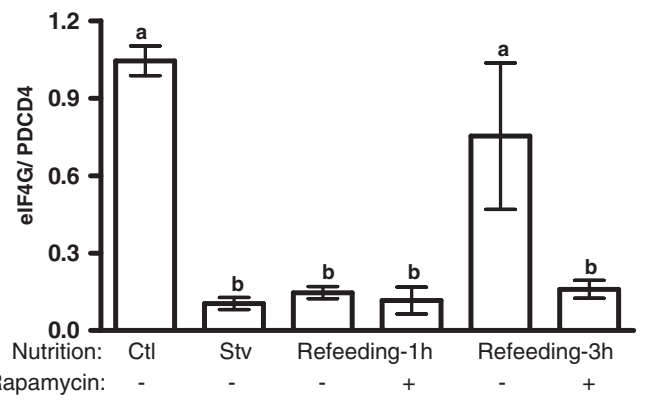

Figure 4 Interaction of PDCD4 with elF4A or elF4G in myotubes. Myotubes were incubated in differentiation (Ctl) or starvation (serum- and amino acid-free) medium for $12 \mathrm{~h}$. They were then harvested (Stv) or refed in the differentiation medium in the presence of rapamycin for 1 or $3 \mathrm{~h}$. Lysates were immunoprecipitated with either (A) anti elF4A or (C) anti PDCD4 antibodies followed by western blotting. Signals from immunoprecipitates were quantified and shown in $\mathbf{B}, \mathbf{D}$ and $\mathbf{E}$. Means $\pm \mathrm{SE} ; \mathrm{n}=4$; bars with different letters differ $(P<0.05)$. 


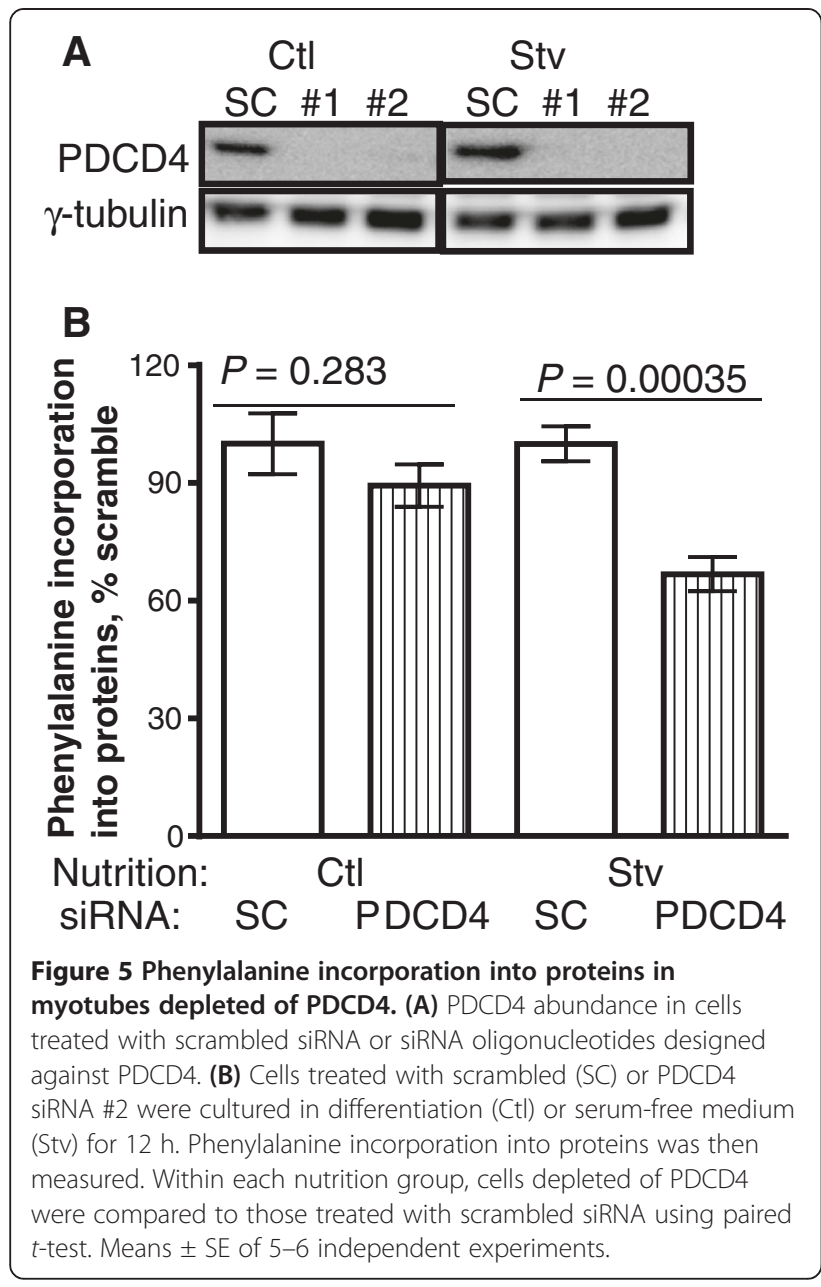

values in those treated with PDCD4 siRNA \#2 was $67 \%$ of those treated with scrambled siRNA $(\mathrm{P}=0.00035$, Figure 5B). In another experiment, PDCD4 deprived cells were incubated in medium lacking both serum and amino acids (RPMI 1640). Incorporation of phenylalanine into myotube total mixed proteins in cells treated with the two PDCD4 siRNA oligonucleotides was 72$80 \%$ of the values in cells treated with scrambled siRNA oligonucleotides (data not shown). Finally we examined the effect of PDCD4 on the regulation of myofibrillar proteins. Depletion of PDCD4 led to a 30\% reduction in phenylalanine incorporation into myofibrillar proteins (see Additional file 2).

The finding of reduced protein synthesis in cells deprived of PDCD4 was surprising given the inhibitory role of this protein on mRNA translation and our previous finding in myoblast. Thus we carried out two additional control experiments. First, we repeated the myoblast experiments and showed that as before, in starved cells, PDCD4 depletion increased protein synthesis by $43 \%$ (Figure 6A). Finally, we used siRNA oligonucleotides purchased from another company (Life Technologies,
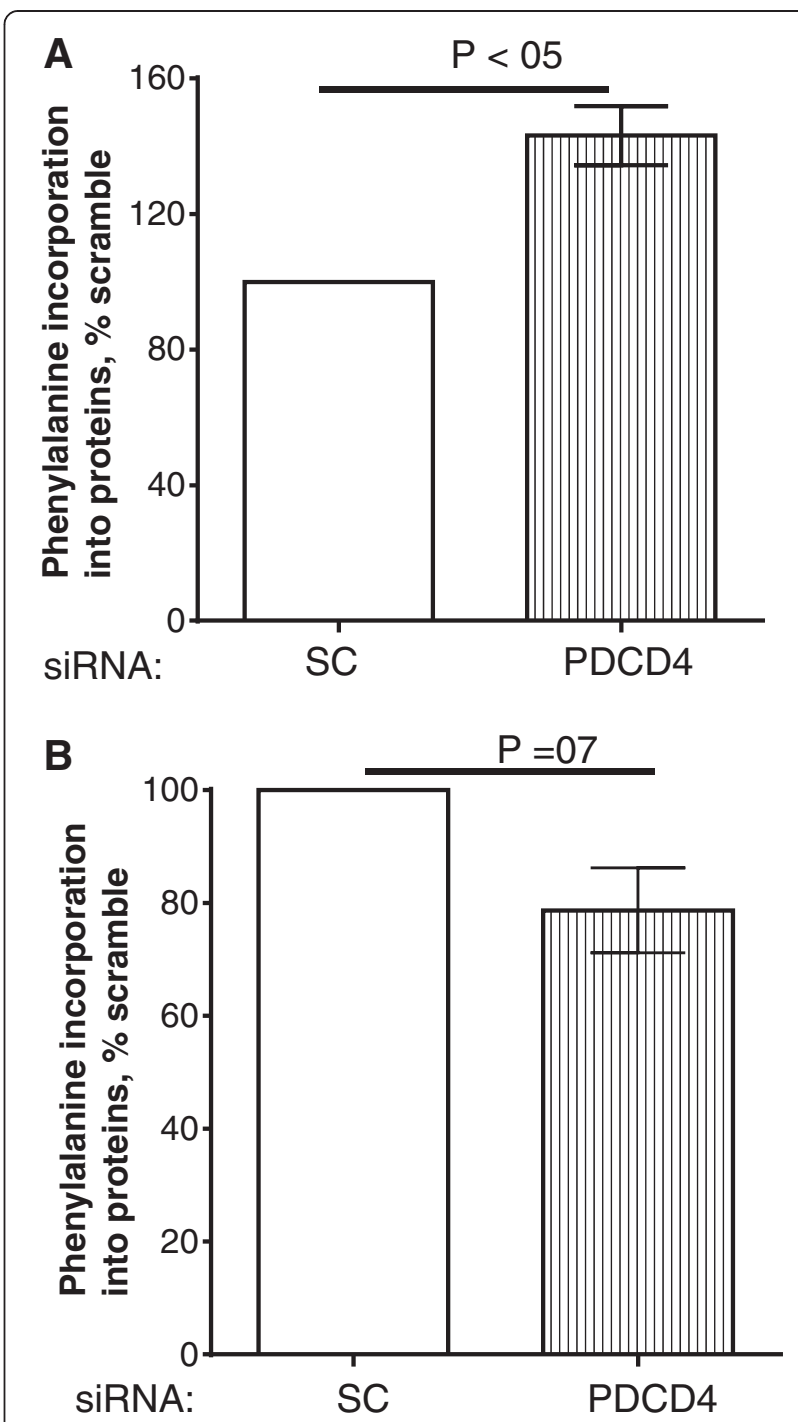

Figure 6 Phenylalanine incorporation into proteins in myoblasts and myotubes depleted of PDCD4. (A) $L 6$ myoblasts were treated with scrambled (SC) or PDCD4 oligonucleotides as described in Figure 5. Cells were then deprived of amino acids and serum for $12 \mathrm{~h}$, after which phenylalanine incorporation into proteins was measured. (B) Myotubes were treated as in Figure 5 except that siRNA oligonucleotides obtained from Life Technologies were used. Data are expressed as \% of SC. Means \pm SE of 3-4 independent experiments.

Burlington Ontario Canada) to silence PDCD4 in myotubes. Protein synthesis in myotubes deprived of PDCD4 was reduced by $21 \%(P=0.07$, Figure $6 \mathrm{~B})$.

To gain insight into the mechanisms of effect of PDCD4 knockdown on myotube protein synthesis, we examined the regulation of components of mTORC1 signalling and mRNA translation initiation. Although starvation predictably reduced the phosphorylation of 4E-BP1 and increased the binding of $4 \mathrm{E}-\mathrm{BP} 1$ to eIF4E, PDCD4 depletion had no effects on these parameters (Figure 7A). Likewise, in 

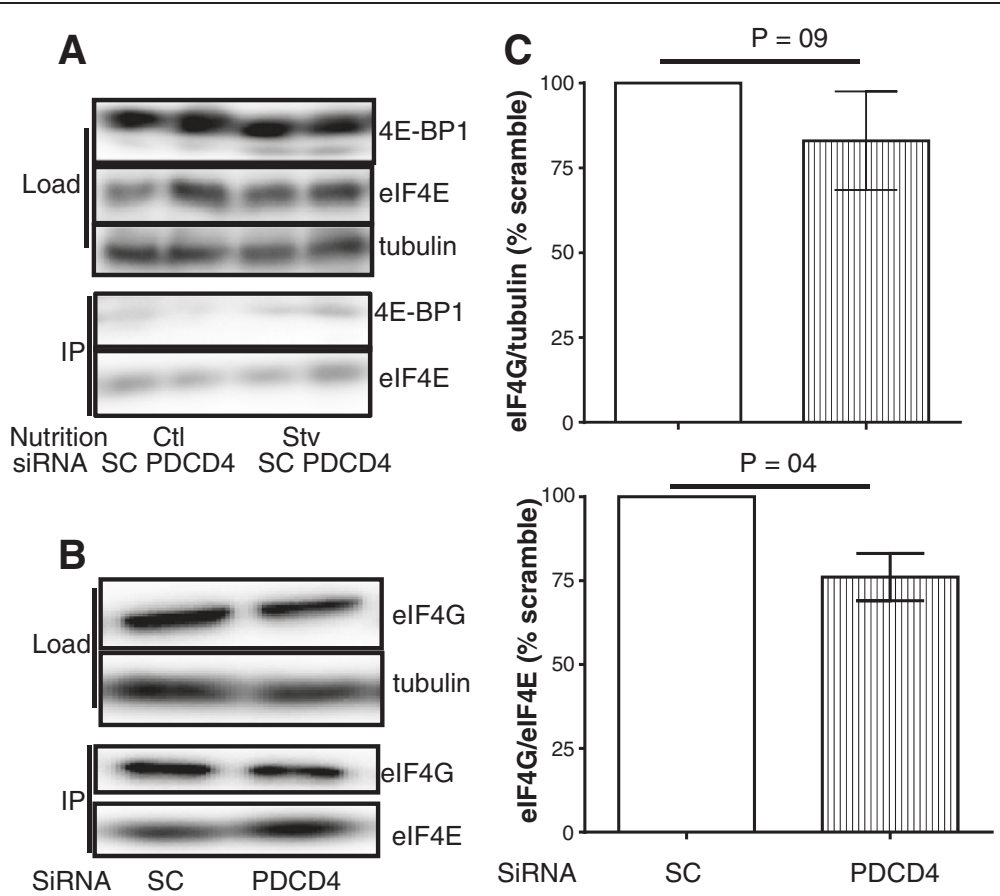

Figure 7 Abundance of translation initiation factors and interaction of elF4G with elF4E in myotubes depleted of PDCD4. Cells were treated with scrambled (SC) or PDCD4 oligonucleotides as in Figures 5 and 6. They were then deprived of amino acids and serum for $12 \mathrm{~h}$. (A) Abundance of 4E-BP1 and elF4E, and interaction of the two were measured. Reduced phosphorylation of 4E-BP1 is obvious in downward shifts of signals in lanes for starved cells (compare lanes 1 and 2 to lanes 3 and 4 in the top panel of Figure 7A). (B) Abundance of elF4G and its interaction with elF4E. (C) Quantification of elF4G abundance (upper chart; tubulin served as loading control) and its interaction with elF4E (lower). Data are expressed as \% of SC. Means \pm SE of 3 independent experiments.

starved myotubes, PDCD4 depletion had no effect on S6K1 or S6 phosphorylation (data not shown). However, there was a trend towards reduced eIF4G in cells depleted of PDCD4 (17\% lower compared to Scramble, $\mathrm{P}=0.09$ ). Furthermore, PDCD4 depletion significantly reduced eIF4G interaction with eIF4E (Figure 7B and C).

\section{Discussion}

In this study, we demonstrated that in myotubes, the regulation of PDCD4 abundance was reversibly modified by a starvation-refeeding cycle. Collectively, the data presented here are the first evidence to demonstrate a requirement for $\mathrm{mTORC} 1$ and the proteasome in regulating the abundance of PDCD4 in muscle cells. We also presented evidence that, at least in myotubes, in the absence of growth factors, amino acids had little effect in regulating the abundance of this protein. Finally, in starved myotubes, and contrary to observations in myoblasts [20] and non muscle cells [12], depletion of PDCD4 had minimal effect on the incorporation of phenylalanine into myotube proteins. Rather, in starved myotubes, PDCD4 depletion further reduced eIF4G binding to eIF4E.

In spite of the fact that PDCD4 has been characterized as a substrate of S6K1 and an inhibitor of cap-dependent mRNA translation initiation, there is a paucity of information on the significance of PDCD4 in skeletal muscle. Also, it is unknown if the regulation of PDCD4, like mTORC1/ S6K1, is sensitive to nutrients. In the present study, Ser67 and Ser457 phosphorylation of PDCD4 correlates poorly with its abundance. A requirement for mTORC1/S6K1 in regulating PDCD4 abundance suggests that PDCD4 may be phosphorylated on additional residues. However, PDCD4 degradation appears to depend specifically on Ser67 phosphorylation [12]. It is also possible that phosphorylated PDCD4 does not accumulate because degradation by the proteasome is very rapid. However, in refed cells treated with MG132, Ser67 phosphorylated PDCD4 did not accumulate to a greater extent in comparison with cells not treated with the drug (data not shown).

Although amino acids can activate mTORC1 [23,24], the effects of amino acids require some amount of insulin [25-28]. Our finding that leucine or a medium that contained all the 20 amino acids but lacked growth factors had insignificant effects on PDCD4 abundance is consistent with this view. AKT too may phosphorylate PDCD4 and target it for degradation [29]. In fact, a requirement for serum rather than amino acids might implicate AKT rather than mTORC1/S6K1 in the phosphorylation and degradation of PDCD4 since AKT does not require amino acid for its activation [30]. However, incubation 
with rapamycin would not only inhibit mTORC1/S6K1 but should lead to a greater activation of PI3K-AKT pathway due to the loss of negative inhibition conveyed by activated S6K1 (reviewed in [31]). In our study, the fact that inhibition with rapamycin during a 1-h refeeding completely prevented the disappearance of PDCD4 clearly suggests that mTORC1/S6K1 is the main pathway that targets PDCD4 for degradation in myotubes.

Our data showing that PDCD4 knock down suppressed incorporation of phenylalanine into myotube mixed proteins are surprising, given the characterization of the protein as an mRNA translation initiation inhibitor. Furthermore, depletion of PDCD4 in myoblasts ([20] and Figure 6) and in non muscle cells [12] increases protein synthesis. A possible explanation might be that the regulation of myofibrillar proteins, the predominant proteins in myotubes, is different from that of total protein. However, we showed that incorporation of phenylalanine into myofibrillar proteins in cells depleted of PDCD4 was 30\% lower compared with cells with normal level of PDCD4 (see Additional file 2). We did not measure the rate of synthesis of sarcoplasmic proteins; nevertheless, our data showing a suppression of phenylalanine incorporation into total and myofibrillar proteins suggest that even if depletion of PDCD4 increased the synthesis of sarcoplasmic proteins, such an increase was likely too small to offset the decrease in myofibrillar protein synthesis. It is not clear how PDCD4 depletion would regulate eIF4G abundance and interaction with eIF4E, although there is evidence that PDCD4 can transcriptionally regulate the abundance of some proteins [11]. However, there is no evidence that eIF4G is one of such proteins.

Combined with data from myoblasts and non muscle cells, our data suggest that the effect of PDCD4 on protein synthesis may depend on cell type and/or stage of development, as previously suggested [22]. In this regard, although PDCD4 has been implicated in regulating the abundance of some proteins, including p21 (Waf1/Cip1) [32] and lysyl oxidase [33], only c-myb [34], procaspase-3 [35] and p53 [36] have been demonstrated as natural mRNA translation substrates of PDCD4. These are all factors involved in regulating cell proliferation and migration, and therefore of more relevance in proliferating cells. This is consistent with the notion that the effect of PDCD4 on mRNA translation and protein synthesis might depend on the physiological state of the cell. However, PDCD4 and its targets may still be relevant in regulating muscle protein synthesis and mass during muscle development and regeneration. For example during muscle hypertrophy or repair following injury, satellite cells need to be activated, leading to the proliferation of myoblasts that will subsequently fuse to form myotubes [37]. These can then fuse with existing myofibers or be used to form new fibers $[38,39]$. PDCD4 might be involved in this regulation.
Consistent with this, abundance of PDCD4 increases during initiation of L6 differentiation into myotubes (Abdullahi A. and Adegoke O.A.J., unpublished observations).

\section{Conclusions}

We showed that in L6 myotubes, the regulation of PDCD4 abundance by nutritional factors is sensitive to mTORC1 and ubiquitin dependent proteolytic system. In the absence of growth factors, amino acids, including leucine, appear to play a minor role in regulating PDCD4 abundance. Unlike in proliferating myoblasts and non muscle cells, depletion of PDCD4 had, at best, only modest effect on myotube protein synthesis, indicating that the effect of PDCD4 in muscle cells is dependent on the physiological state of the cell. Additional studies are needed to dissect the mechanisms behind these differential effects of PDCD4.

\section{Methods}

\section{Reagents}

Fetal Bovine Serum (FBS), Horse Serum (HS), Lipofectamine RNAi ${ }^{\mathrm{Max}}$, Opti-MEM medium, and antibiotic/antimycotic reagents were purchased from Life Technologies (Burlington, Ontario Canada). Amino acid-free medium (RPMI 1640) was obtained from US Biological (Swampscott MA, USA). PDCD4 siRNA oligonucleotides, phosphatase and protease inhibitor cocktails were purchased from Sigma-Aldrich (St. Louis, MO, USA). Alpha Modification of Eagle's Medium (AMEM) was obtained from Wisent (St-Bruno, Quebec, Canada).

\section{Antibodies}

Antibodies to eIF4A, eIF4G, phosphorylated (Thr389) S6K1, and horseradish peroxidase (HRP)-conjugated secondary antibodies (anti-rabbit and anti-mouse) were purchased from Cell Signaling Technology (Danvers, Massachusetts, USA). Antibody against PDCD4 was from Cell Signaling Technology or Santa Cruz Biotechnology (Santa Cruz, California, USA). Antibodies against phosphorylated (Ser67, Ser457) PDCD4 were from SigmaAldrich or Aviva Systems Biology (San Diego, California, USA).

\section{Cell culture}

L6 myoblasts were cultured in 12-well plates in growth medium (GM: AMEM supplemented with FBS and antibiotic-antimycotic agents to final concentrations of 10 and $1 \%$, respectively) until they reached $\sim 80 \%$ confluency. Cells were then shifted into differentiation medium (DM: AMEM as above except that $2 \%$ HS replaced 10\% FBS). Experiments were carried out on day 4-5 of differentiation. For starvation experiments, myotubes were grown in differentiation medium or starved in amino-acid free, serum-free medium (amino acid-free RPMI 1640) for 
$12 \mathrm{~h}$. They were then refed in DM for 1 or $3 \mathrm{~h}$. To examine the roles of amino acids and growth factors in regulating PDCD4 abundance, in some experiments refeeding was done in incubation media of varied composition. To examine the requirement for mTORC1 or the ubiquitin dependent proteolytic system on the regulation of PDCD4, additional refeeding experiments were carried out in the presence of inhibitors of these pathways (50 nM rapa-

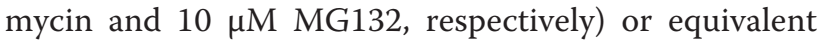
volumes of DMSO. At the end of the experiments, cells were harvested in a lysis buffer (25 mM Tris, $\mathrm{pH} 7.5$, $1 \mathrm{mM}$ EDTA, 2\% (w/v) sodium dodecyl sulphate (SDS), $1 \mathrm{mM}$ DTT, supplemented with protease $(10 \mu \mathrm{l} / \mathrm{mL})$ and phosphatase $(10 \mu \mathrm{l} / \mathrm{mL})$ inhibitor cocktails $)$.

\section{RNA interference}

Myotubes on day 4 of differentiation were transfected with $30 \mathrm{nM}$ siRNA oligonucleotides designed against PDCD4 or with a proprietary scrambled oligonucleotide ((Sigma Aldrich, Oakville, Ontario Canada)), using Lipofectamine $\mathrm{RNAi}^{\mathrm{Max}}$ (Life Technologies) as previously described [20]. We used the following PDCD4 siRNA oligonucleotides: PDCD4 \#1 sense (GUCUUCUACUAU UACCAUA [dT] [dT]), PDCD4 \#1 antisense (5'UAUGG UAAUAGUAGAAGAC [dT] [dT]), PDCD4 \#2 sense (CUACUAUUACCAUAGACCA [dT] [dT]), and PDCD4 \#2 antisense (UGGUCUAUGGUAAUAGUAG [dT] [dT]. Thirty eight hours after transfection, cells were cultured in DM or starvation medium. Phenylalanine incorporation into proteins was then measured by assessing the incorporation of radioactive phenylalanine into trichloroacetic acid (TCA) precipitable proteins $[29,40]$.

\section{Western blotting and immunoprecipitation}

Proteins were resolved on $7.5,10$, or $15 \%$ SDS-PAGE (depending on the antigens being studied), transferred onto polyvinylidene difluoride (PVDF) membranes, which were then immunoblotted for the indicated antigens, as previously described [20]. Immunoblot signals were quantified using the Carestream Molecular Imaging software (version 5.0.2.30, Carestream Health Inc., Rochester, New York, USA).

To immunoprecipitate eIF4A or PDCD4, myotubes were cultured in $10-\mathrm{cm}$ plates. Following appropriate treatments, cells were rinsed in ice-cold PBS and then lysed in $500 \mu \mathrm{l}$ of ice-cold lysis buffer (40 mm HEPES ( $\mathrm{pH} 7.5$ ), $120 \mathrm{mM} \mathrm{NaCl}, 1 \mathrm{mM}$ EDTA, $10 \mathrm{mM}$ pyrophosphate, $10 \mathrm{mM}$ glycerol 2 phosphate, $0.5 \mathrm{mM}$ orthovanadate) supplemented with $0.03 \%$ CHAPS, $1 \mathrm{mM}$ DTT, $0.5 \mathrm{mM} \mathrm{NaV}$, $1 \mathrm{mM}$ benzamidine, $6.25 \mathrm{mM}$ N-ethyl-maleimide (NEM) and protease inhibitor cocktail $(10 \mu \mathrm{L} / \mathrm{mL})$. One hundred micrograms of myotube proteins were combined with either anti eIF4A or anti-PDCD4 (Santa Cruz biotechnology) antibodies and the mix rotated overnight at $4^{\circ} \mathrm{C}$. The following day and in order to precipitate the antigenantibody complex, $50 \mu \mathrm{L}$ of re-suspended BioMag protein G-bound beads (GE Healthcare, Baie d'Urfe, Quebec, Canada) were added to each of the immunoprecipitation tubes and the suspension rocked gently at $4^{\circ} \mathrm{C}$ for $1 \mathrm{~h}$. The beads were collected on a magnetic stand (Life Technologies) and washed 3 times with $0.1 \mathrm{M}$ sodium phosphate buffer. After the last wash, beads were re-suspended in $1 \mathrm{X}$ SDS-PAGE sample buffer and boiled at $95^{\circ} \mathrm{C}$ for 2 minutes. Following a brief centrifugation, eluates were collected, separated on 10\% SDS-PAGE, and blotted for PDCD4 and eIF4A.

\section{Statistics}

Data are presented as means \pm SEM. Treatment means were compared using a one-way analysis of variance (ANOVA) and differences among individual means assessed using the Bonferroni multiple comparison test or, as in Figures 5, 6 and 7, by paired Students T-tests. Analyses were done using GraphPAD (Version 6, GraphPAD Software, La Jolla California, USA). The level of significance was set at $\mathrm{P}<0.05$.

\section{Additional files}

Additional file 1: PDCD4 phosphorylation (Ser457) in L6 myotubes.

Additional file 2: Myofibrillar protein synthesis in L6 myotubes.

\section{Competing interest}

The authors declare that they have no competing interest.

\section{Authors' contributions}

OAJA conceived, designed, conducted experiments, wrote and reviewed the manuscript; DK, NI and NM conducted experiments and reviewed the manuscript. All authors read and approved the final version of the manuscript.

\section{Acknowledgments}

This work was supported by the Natural Sciences and Engineering Research Council of Canada Discovery Grant [\#355984] and Faculty of Health York

University Minor Research Grants to Olasunkanmi A.J. Adegoke.

Received: 1 November 2013 Accepted: 4 January 2014

Published: 9 January 2014

\section{References}

1. Adegoke OA, Abdullahi A, Tavajohi-Fini P: mTORC1 and the regulation of skeletal muscle anabolism and mass. Appl Physiol Nutr Metab 2012, 37(3):395-406

2. Glass $D$, Roubenoff R: Recent advances in the biology and therapy of muscle wasting. Ann N Y Acad Sci 2010, 1211(1):25-36.

3. Ray BN, Kweon HK, Argetsinger LS, Fingar DC, Andrews PC, Carter-Su C: Research resource: identification of novel growth hormone-regulated phosphorylation sites by quantitative phosphoproteomics. Mol Endocrinol 2012, 26(6):1056-1073.

4. Sengupta S, Peterson TR, Sabatini DM: Regulation of the mTOR complex 1 pathway by nutrients, growth factors, and stress. Mol Cell 2010, 40(2):310-322.

5. Kimball SR, Jefferson LS: Control of translation initiation through integration of signals generated by hormones, nutrients and exercise. J Biol Chem 2010, 285(38):29027-29032. doi: 10.1074/jbc.R110.137208. Epub 2010 Jun 24. Review. 
6. Mieulet V, Roceri M, Espeillac C, Sotiropoulos A, Ohanna M, Oorschot V, Klumperman J, Sandri M, Pende M: S6 kinase inactivation impairs growth and translational target phosphorylation in muscle cells maintaining proper regulation of protein turnover. Am J Physiol Cell Physiol 2007, 293(2):C712-C722

7. Ruvinsky I, Meyuhas O: Ribosomal protein S6 phosphorylation: from protein synthesis to cell size. Trends Biochem Sci 2006, 31(6):342-348.

8. Onishi Y, Hashimoto S, Kizaki H: Cloning of the TIS gene suppressed by topoisomerase inhibitors. Gene 1998, 215(2):453-459.

9. Yoshinaga $\mathrm{H}$, Matsuhashi S, Fujiyama C, Masaki Z: Novel human PDCD4 (H731) gene expressed in proliferative cells is expressed in the small duct epithelial cells of the breast as revealed by an anti-H731 antibody. Pathol Int 1999, 49(12):1067-1077.

10. Azzoni L, Zatsepina O, Abebe B, Bennett IM, Kanakaraj P, Perussia B: Differential transcriptional regulation of CD161 and a novel gene, 197/15a, by IL-2, IL-15, and IL-12 in NK and T cells. J Immunol 1998, 161(7):3493-3500

11. Allgayer $\mathrm{H}$ : Pdcd4, a colon cancer prognostic that is regulated by a microRNA. Crit Rev Oncol Hematol 2010, 73(3):185-191.

12. Dorrello NV, Peschiaroli A, Guardavaccaro D, Colburn NH, Sherman NE, Pagano M: S6K1- and betaTRCP-mediated degradation of PDCD4 promotes protein translation and cell growth. Science 2006, 314(5798):467-471.

13. Yang HS, Cho MH, Zakowicz H, Hegamyer G, Sonenberg N, Colburn NH: A novel function of the MA-3 domains in transformation and translation suppressor Pdcd4 is essential for its binding to eukaryotic translation initiation factor 4A. Mol Cell Biol 2004, 24(9):3894-3906.

14. Yang HS, Jansen AP, Komar AA, Zheng X, Merrick WC, Costes S, Lockett SJ, Sonenberg N, Colburn NH: The transformation suppressor Pdcd4 is a novel eukaryotic translation initiation factor $4 \mathrm{~A}$ binding protein that inhibits translation. Mol Cell Biol 2003, 23(1):26-37.

15. Lankat-Buttgereit B, Goke R: The tumour suppressor Pdcd4: recent advances in the elucidation of function and regulation. Biol Cell 2009, 101(6):309-317.

16. Wei NA, Liu SS, Leung TH, Tam KF, Liao XY, Cheung AN, Chan KK, Ngan HY: Loss of programmed cell death 4 ( $(\mathrm{Cdcd} 4)$ associates with the progression of ovarian cancer. Mol Cancer 2009, 8:70.

17. Chen Y, Knösel T, Kristiansen G, Pietas A, Garber ME, Matsuhashi S, Ozaki I, Petersen I: Loss of PDCD4 expression in human lung cancer correlates with tumour progression and prognosis. J Pathol 2003, 200(5):640-646.

18. Afonja O, Juste D, Das S, Matsuhashi S, Samuels HH: Induction of PDCD4 tumor suppressor gene expression by RAR agonists, antiestrogen and HER-2//neu antagonist in breast cancer cells. Evidence for a role in apoptosis. Oncogene 2004, 23(49):8135-8145.

19. Zhang $S$, Li J, Jiang $Y, X u Y$, Qin C: Programmed cell death 4 (PDCD4) suppresses metastastic potential of human hepatocellular carcinoma cells. J Exp Clin Cancer Res 2009, 28:71

20. Zargar S, Moreira TS, Samimi-Seisan H, Jeganathan S, Kakade D, Islam N, Campbell J, Adegoke OA: Skeletal muscle protein synthesis and the abundance of the mRNA translation initiation repressor PDCD4 are inversely regulated by fasting and refeeding in rats. Am J Physiol Endocrinol Metab 2011, 300(6):E986-E992.

21. Shi J, Luo L, Eash J, Ibebunjo C, Glass DJ: The SCF-Fbxo40 complex induces IRS1 ubiquitination in skeletal muscle, limiting IGF1 signaling. Dev Cell 2011, 21(5):835-847.

22. Lankat-Buttgereit B, Lenschen B, Schmidt H, Goke R: The action of Pdcd4 may be cell type specific: evidence that reduction of dUTPase levels might contribute to its tumor suppressor activity in Bon-1 cells. Apoptosis 2008, 13(1):157-164.

23. Blommaart EF, Luiken JJ, Blommaart PJ, van Woerkom GM, Meijer AJ: Phosphorylation of ribosomal protein $\mathrm{S} 6$ is inhibitory for autophagy in isolated rat hepatocytes. J Biol Chem 1995, 270(5):2320-2326.

24. Hara K, Yonezawa K, Weng QP, Kozlowski MT, Belham C, Avruch J: Amino acid sufficiency and mTOR regulate p70 S6 kinase and eIF-4E BP1 through a common effector mechanism. J Biol Chem 1998, 273(23):14484-14494.

25. Bolster DR, Jefferson LS, Kimball SR: Regulation of protein synthesis associated with skeletal muscle hypertrophy by insulin-, amino acid- and exercise-induced signalling. Proc Nutr Soc 2004, 63(2):351-356.

26. Crozier SJ, Kimball SR, Emmert SW, Anthony JC, Jefferson LS: Oral leucine administration stimulates protein synthesis in rat skeletal muscle. J Nutr 2005, 135(3):376-382

27. Meijer AJ, Dubbelhuis PF: Amino acid signalling and the integration of metabolism. Biochem Biophys Res Commun 2004, 313(2):397-403.
28. Rennie MJ, Bohe J, Smith K, Wackerhage H, Greenhaff P: Branched-chain amino acids as fuels and anabolic signals in human muscle. J Nutr 2006 136(1 Suppl):264S-268S.

29. el-Naggar EA, Kanda F, Okuda S, Maeda N, Nishimoto K, Ishihara H, Chihara K: Direct effects of tumor necrosis factor alpha (TNF-alpha) on L6 myotubes. Kobe J Med Sci 2004, 50(1-2):39-46.

30. Nobukuni T, Joaquin M, Roccio M, Dann SG, Kim SY, Gulati P, Byfield MP, Backer JM, Natt F, Bos JL, et al: Amino acids mediate mTOR/raptor signaling through activation of class 3 phosphatidylinositol $30 \mathrm{H}$-kinase. Proc Natl Acad Sci U S A 2005, 102(40):14238-14243.

31. Guertin DA, Sabatini DM: The pharmacology of mTOR inhibition. Sci Signal 2009, 2(67):e24.

32. Bitomsky N, Wethkamp N, Marikkannu R, Klempnauer KH: siRNA-mediated knockdown of Pdcd4 expression causes upregulation of p21(Waf1/Cip1) expression. Oncogene 2008, 27(35):4820-4829.

33. Santhanam AN, Baker AR, Hegamyer G, Kirschmann DA, Colburn NH: Pdcd4 repression of lysyl oxidase inhibits hypoxia-induced breast cancer cell invasion. Oncogene 2010, 29(27):3921-3932.

34. Singh $\mathrm{P}$, Wedeken $\mathrm{L}$, Waters $\mathrm{LC}$, Carr MD, Klempnauer KH: Pdcd4 directly binds the coding region of c-myb mRNA and suppresses its translation. Oncogene 2011, 30(49):4864-4873.

35. Eto K, Goto S, Nakashima W, Ura Y, Abe SI: Loss of programmed cell death 4 induces apoptosis by promoting the translation of procaspase- 3 mRNA. Cell Death Differ 2012, 19(4):573-581.

36. Wedeken L, Singh P, Klempnauer KH: Tumor suppressor protein Pdcd4 inhibits translation of p53 mRNA. J Biol Chem 2011, 286(50):42855-42862.

37. Zammit PS, Partridge TA, Yablonka-Reuveni Z: The skeletal muscle satellite cell: the stem cell that came in from the cold. J Histochem Cytochem 2006, 54(11):1177-1191.

38. Dhawan J, Rando TA: Stem cells in postnatal myogenesis: molecular mechanisms of satellite cell quiescence, activation and replenishment. Trends Cell Biol 2005, 15(12):666-673.

39. Kadi F, Ponsot E: The biology of satellite cells and telomeres in human skeletal muscle: effects of aging and physical activity. Scand J Med Sci Sports 2010, 20(1):39-48.

40. Gulve EA, Dice JF: Regulation of protein synthesis and degradation in L8 myotubes. Effects of serum, insulin and insulin-like growth factors. Biochem J 1989, 260(2):377-387.

doi:10.1186/1471-2121-15-2

Cite this article as: Kakade et al: Differential effects of PDCD4 depletion on protein synthesis in myoblast and myotubes. BMC Cell Biology 2014 15:2.

\section{Submit your next manuscript to BioMed Central and take full advantage of:}

- Convenient online submission

- Thorough peer review

- No space constraints or color figure charges

- Immediate publication on acceptance

- Inclusion in PubMed, CAS, Scopus and Google Scholar

- Research which is freely available for redistribution 